\title{
A New Strategy to Pretreat Carbon Nanofiber and Its Application in Determination of Dopamine
}

\author{
Dong Liu, ${ }^{1}$ Yang Liu, ${ }^{1}$ Haoqing Hou, ${ }^{2}$ and Tianyan You ${ }^{1}$ \\ ${ }^{1}$ State Key Laboratory of Electroanalytical Chemistry, Changchun Institute of Applied Chemistry, Chinese Academy of Sciences, \\ 5625 Renmin Street, Changchun, Jilin 130022, China \\ ${ }^{2}$ College of Chemistry and Chemical Engineering, Jiangxi Normal University, Nanchang 330027, China
}

Correspondence should be addressed to Tianyan You, youty@ciac.jl.cn

Received 31 May 2010; Accepted 18 July 2010

Academic Editor: Rakesh Joshi

Copyright (C) 2010 Dong Liu et al. This is an open access article distributed under the Creative Commons Attribution License, which permits unrestricted use, distribution, and reproduction in any medium, provided the original work is properly cited.

\begin{abstract}
A novel sonochemical process, using hydrogen peroxide in a laboratory ultrasonic bath, was employed to pretreat the carbon nanofiber (CNF) for creating oxygen-rich groups on the surface of CNF. After the sonochemical process, the CNF showed good hydrophilicity and high electrochemical activity. Compared to normal pretreatment process, this sonochemical process is timesaving and effective for dispersion and functionalization of CNF. The resulting CNF showed high catalytic activity toward the oxidation of DA. A carbon paste electrode modified by CNF (CPE-CNF) was used to determine the dopamine (DA) in the presence of ascorbic acid (AA). The detection limit is $0.05 \mu \mathrm{M}$, with the linear range from $0.05 \mu \mathrm{M}$ to $6.4 \mu \mathrm{M}$.
\end{abstract}

\section{Introduction}

Carbonaceous materials, especially carbon nanotube (CNT), attracted great research interests, and lots of investigations have been done in the field of chemical biosensors and fuel cells. Comparing with CNT, carbon nanofiber (CNF) exhibits unique mechanical and catalytic properties, high electrical conductivity, and chemical stability. However, due to the hydrophobicity of CNF surface, the pristine CNF is difficult to be dispersed in the water. As a result, it is necessary to treat CNF for improving the hydrophilicity. Acidic mixture solution is mostly used to treat CNF. So far, the functionalization is carried out by the pretreatment of CNF in $\mathrm{HCl}, \mathrm{HNO}_{3}$, and $\mathrm{KOH}$ for improving its hydrophilicity [1]. As for CNT, a sonochemical process has already been developed to treat $\mathrm{CNT}$ in the acidic mixture solution to create oxygen-rich groups for depositing metal nanoparticle [2], which is found to be timesaving and effective. Except for the acidic mixture solution, hydrogen peroxide $\left(\mathrm{H}_{2} \mathrm{O}_{2}\right)$ solution is also used to modify the CNT [3]. The results indicated that the aldehydic groups formed on the CNT after treated with the $\mathrm{H}_{2} \mathrm{O}_{2}$ solution, but the hydroxyl bands ($\mathrm{OH})$ and the aldehydic groups $(<\mathrm{C}=\mathrm{O})$ formed after treated with the acidic mixture solution. Although the pretreatment using acidic mixture solution has verified its feasibility, such a method is time-consuming and complicated. It is necessary to develop a new way to treat CNF for improving the hydrophilicity, which should be simple and effective.

Dopamine (DA) takes an important part in the functioning of the human metabolism, central nervous and renal systems [4]. DA possesses high electrochemical activity and has been widely studied by electroanalytical techniques [5]. However, ascorbic acid (AA) always coexists with DA in the human body, and the oxidation potential of $\mathrm{AA}$ is close to that of DA. As a result, it is difficult to determine these two species separately using conventional electrodes. A large number of attempts have already been made for the determination of DA sensitively and selectively. Lots of new materials, such as $\mathrm{C}_{60}$-functionalized multiwalled carbon nanotube films [6], the boron-doped carbon nanotubes [7], polymer film [8], and self-assembled monolayer [9], were applied to detect DA in the presence of AA. Moreover, at a physiological $\mathrm{pH}, \mathrm{DA}(\mathrm{pKa}=8.9)$ is positively charged, yet AA $(\mathrm{pKa}=4.2)$ is negatively charged, when the electrode surface is negatively charged, DA can be adsorbed and detected selectively [10]. Some materials, such as nafion, clay [11], and polymeric films [12], were precoated on the surface of the electrode so as to make it negatively charged. 
We applied $\mathrm{H}_{2} \mathrm{O}_{2}$ solution to treat CNF in a laboratory ultrasonic bath. Comparing with normal acid pretreatment, this method is timesaving, and the resulting CNF shows good hydrophilicity. The CNF-modified carbon paste electrode (CNF-CPE) shows high electrochemical activity and large effective electroactive surface area. The CNF-CPE exhibits good electrochemical catalysis toward DA in the presence of $\mathrm{AA}$ and it can detect DA sensitively and selectively. The CNFCPE used for the detection of DA is effective and simple in comparison with other modified electrodes, which may be applied to the practical analysis of DA.

\section{Experiment}

2.1. Materials. Polyacrylonitrile (PAN), dimethylformamide (DMF), and graphite powder $(2 \mu \mathrm{m})$ were purchased from Aldrich. Mineral oil, $30 \% \mathrm{H}_{2} \mathrm{O}_{2}$, and AA were from Beijing Chemical Co. (China), DA from Alfa Aesar. All other reagents were of analytical grade. The phosphate buffer solution was made from $\mathrm{Na}_{2} \mathrm{HPO}_{4}$ and $\mathrm{NaH}_{2} \mathrm{PO}_{4}$. All solutions were prepared by the double-distilled water. The electrochemical measurements were carried out on a CHI 832 electrochemical workstation (Shanghai, China) with a conventional three-electrode system composed of a platinum auxiliary, a $\mathrm{Ag} / \mathrm{AgCl}$ (saturated $\mathrm{KCl}$ ) reference, and a bare or modified carbon paste working electrode.

The surface potential of the treated CNF was estimated by zeta potential measurement (Malvern, Zetasizer ZEN3600). A measurement cell was filled by the suspension of CNF and the $\mathrm{pH}$ of the suspension was controlled by the addition of $\mathrm{HCl}$ solution. The surface of the CNF was analyzed by using X-ray photoelectron spectroscopy (Thermo, ESCALAB 250). A Fourier transform infrared spectrometry (FT-IR) measurement was performed with a Bruker VERTEX 70 spectrometer.

2.2. Preparation of $C N F$. Carbon nanofiber was made from carbonizing the electrospun PAN nanofibers as reported [13]. $2 \mathrm{mg} \mathrm{CNF}$ was put into $4 \mathrm{~mL} 30 \% \mathrm{H}_{2} \mathrm{O}_{2}$ solution. First, the mixture solution was put in a laboratory ultrasonic bath at $50^{\circ} \mathrm{C}$ for 5 minutes to disperse the carbon nanofiber. Then it was stirred for 10 minutes. This mixing and dispersion process was repeated to break big carbon nanofiber aggregates. After then, the mixture solution was stirred for 2 hours to make sure that there was no $\mathrm{H}_{2} \mathrm{O}_{2}$ in the solution. The mixture was separated from the solution in a centrifuge at $9000 \mathrm{rpm}$ and washed with $5.0 \mathrm{~mL}$ of deionized water five times. Finally, the $\mathrm{CNF}$ was dried at $80^{\circ} \mathrm{C}$. The resulting $\mathrm{CNF}$ was dispersed in the water with a concentration of $1 \mathrm{mg} \mathrm{mL}^{-1}$.

2.3. Preparation of Electrodes. The carbon paste electrode (CPE) was prepared by mixing graphite powder and mineral oil $(70: 30, w / w)$, and then the mixture was packed into a pipette tube $(1.5 \mathrm{~mm} \mathrm{ID} ; 1.4 \mathrm{~cm}$ depth). Electrical contact was made by inserting a copper wire. The CNF-CPE was prepared by dropping $15 \mu \mathrm{L}$ CNF $(1 \mathrm{mg} / \mathrm{mL})$ suspension on the surface of CPE and dried at room temperature. The

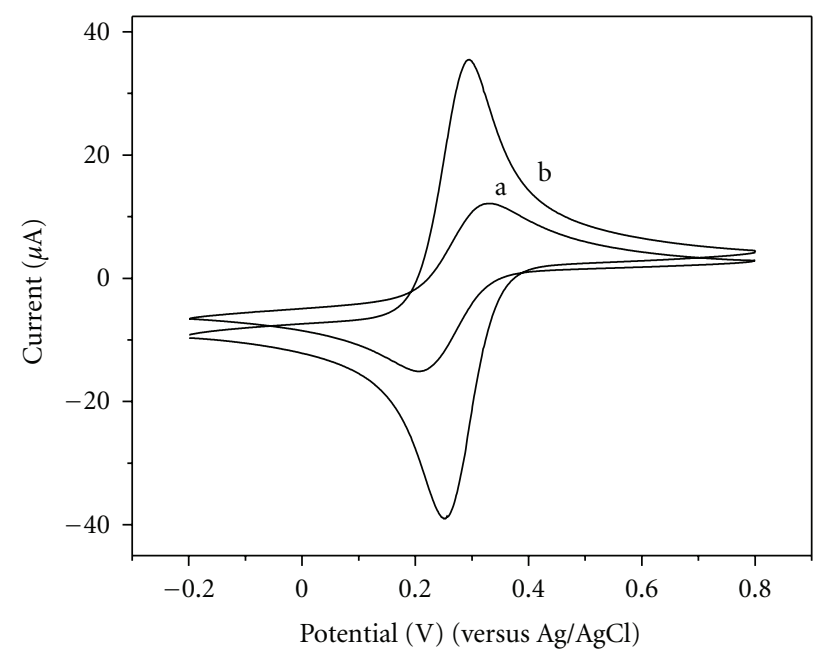

Figure 1: Cyclic voltammograms of $5 \mathrm{mM} \mathrm{K}_{3} \mathrm{Fe}(\mathrm{CN})_{6}$ at the CPE (a) and CNF-CPE (b) Electrolyte, $0.5 \mathrm{M} \mathrm{KCl}$; scan rate, $50 \mathrm{mVs}^{-1}$.

resulting CNF-CPE was rinsed carefully with double-distilled water before each measurement. For comparison, $\mathrm{CPE}$ which was prepared by the same method was used.

\section{Results and Discussion}

3.1. Characterization of CNF-CPE. The modified electrode prepared by a simple procedure was applied to investigate the electrochemical performance of CNF by using $5 \mathrm{mM}$ $\left[\mathrm{Fe}(\mathrm{CN})_{6}\right]^{3-/ 4-}$ redox probe. The cyclic voltammogram for $\left[\mathrm{Fe}(\mathrm{CN})_{6}\right]^{3-/ 4-}$ at CPE (curve a) and CNF-CPE (curve b) was shown in Figure 1. At the CNF-CPE (curve b), a pair of well-defined redox peaks for $\mathrm{Fe}(\mathrm{CN})_{6}{ }^{-3} / \mathrm{Fe}(\mathrm{CN})_{6}{ }^{4-}$ appears at $296 \mathrm{mV}$ and $253 \mathrm{mV}$, and the peak-to-peak separation is $44 \mathrm{mV}$, whereas at the bare CPE the peak-to-peak separation is over $119 \mathrm{mV}$ (Figure 1, curve a). The result demonstrates that the use of CNF can increase the electron transfer rate. In contrast to anodic peak current of the bare $\mathrm{CPE}$, that of CNF-CPE is increased by 2.1-fold, which reveals that the presence of CNF enlarged the effective electroactive surface area. Therefore, the use of CNF significantly improves the reversibility of the redox reaction and enlarges electroactive surface area of the modified electrode which is due to the high electric conductivity of CNF [13]. Although some investigations reveal that $\mathrm{Fe}(\mathrm{CN})_{6}{ }^{-3} / \mathrm{Fe}(\mathrm{CN})_{6}{ }^{4-}$ is not catalyzed by oxygen-rich groups, they do require a specific surface interaction $[14,15]$. It comes to that $\mathrm{Fe}(\mathrm{CN})_{6}{ }^{-3} / \mathrm{Fe}(\mathrm{CN})_{6}{ }^{4-}$ is "surface-sensitive" but not "oxide-sensitive". Meantime, some investigations reveal that the oxygen-rich groups, such as carboxyl and phenol surface groups, are able to absorb platinum ion to the surface of $\mathrm{CNF}$ during $\mathrm{Pt} / \mathrm{CNF}$ synthesis [16].

To confirm the presence of oxygen-rich groups, the $\zeta$ potentials of the treated CNF were measured in aqueous solutions with various pH values. From the plots in Figure 2, it can be confirmed that the treated CNF is negatively charged in deionized water $(\mathrm{pH} \sim 7)$, which implies the 


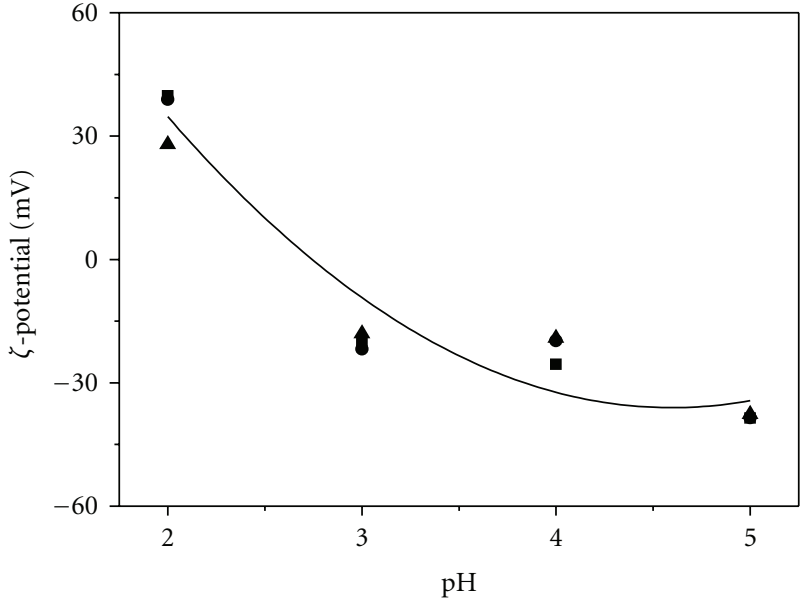

Figure 2: Values of $\zeta$-potential for the water suspension of the treated $\mathrm{CNF}$ at different $\mathrm{pH}$ values.

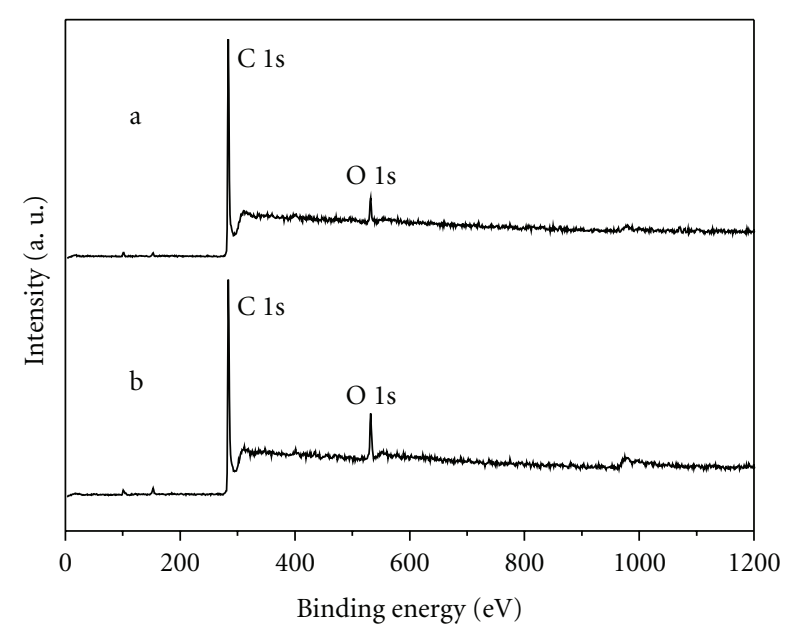

FIgURE 3: XPS scan spectrum of CNF (a) and treated CNF (b).

presence of oxygen-rich groups on the surface of the treated CNF [17], because it is well-known that the oxygen-rich groups formed on the carbon surface would make the surface negatively charged [17]. In addition, XPS was also studied as shown in Figure 3. The oxygen would present as oxygen-rich groups, such as carbonyl and carboxyl groups. The resulting $\mathrm{O} / \mathrm{C}$ atomic ratio for the CNF is 0.0395 , and for the treated $\mathrm{CNF}$ increases to 0.0889 , indicating the pretreatment of CNF results in an increased amount of oxygen content [16]. Finally, a Fourier transform infrared (FT-IR) spectroscopy measurement was conducted for the treated CNF and the result is shown in Figure 4. The band at $1657 \mathrm{~cm}^{-1}$ and $1736 \mathrm{~cm}^{-1}$ can be assigned to carbonyl and carboxyl groups [18]. As for the band at $1546 \mathrm{~cm}^{-1}$, the assignment is not settled [18]. From the above results, it can be concluded that oxygen-rich groups can be created after the treatment. In summary, the high electroactivity of CNF-CPE in this

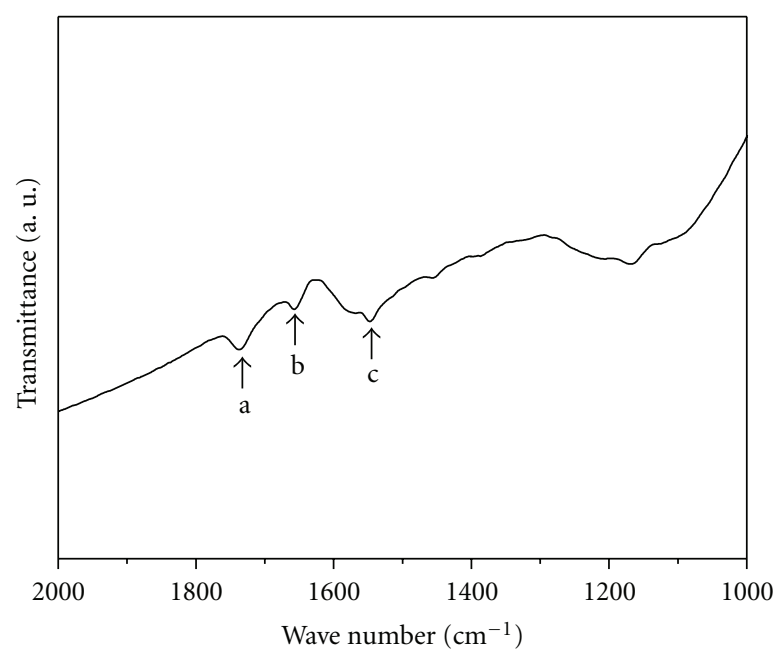

FIGURE 4: IR spectrum of the treated CNF. The three arrows in the figure indicate three IR peaks at 1736 (a), 1657 (b), and 1546 (c) $\mathrm{cm}^{-1}$, respectively.

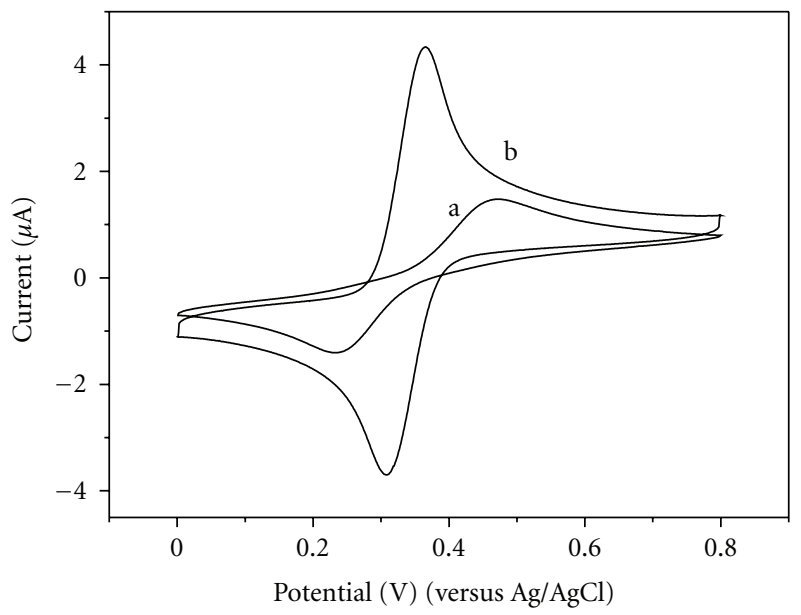

Figure 5: Cyclic voltammograms of DA $(0.2 \mathrm{mM})$ at the CPE (a) and CNF-CPE (b) in $0.1 \mathrm{M}$ PBS (pH 4.5). Scan rate, $50 \mathrm{mV} \mathrm{s}^{-1}$.

experiment can be attributed to the unique surface of $\mathrm{CNF}$ resulting from the oxygen-rich groups on the surface.

3.2. Electrochemical Behavior of Dopamine at CNF-CPE. DA shows high electrochemical activity and has been widely studied by electroanalytical techniques. However, it is difficult to detect DA sensitively and selectively in the presence of AA. In addition, the electrode fouling leads to poor reproducibility and sensitivity, which is due to the adsorption of oxidation product [19]. CNF-CPE was used to investigate the electrochemical behavior of DA in PBS ( $\mathrm{pH}$ 4.5) solution. Figure 5 shows cyclic voltammograms of DA in $0.1 \mathrm{M}$ PBS at the bare CPE (curve a) and CNF-CPE (curve b). It can be observed that DA occurs quasi-reversibly with the anodic and cathodic peak potential at $473 \mathrm{mV}$ and $233 \mathrm{mV}$ at the bare CPE. The peak-to-peak separation is $224 \mathrm{mV}$, indicating the slow electron transfer at the bare CPE. However, the peak 


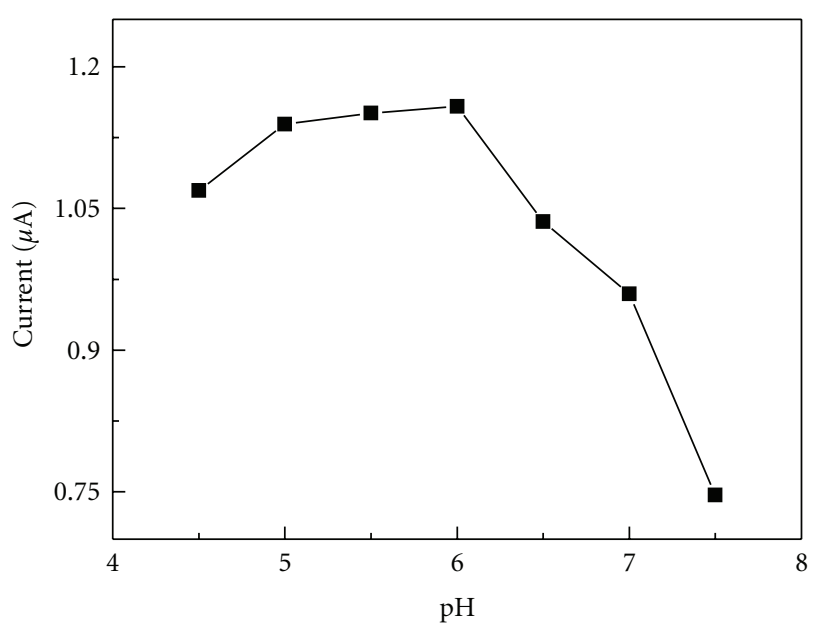

(a)

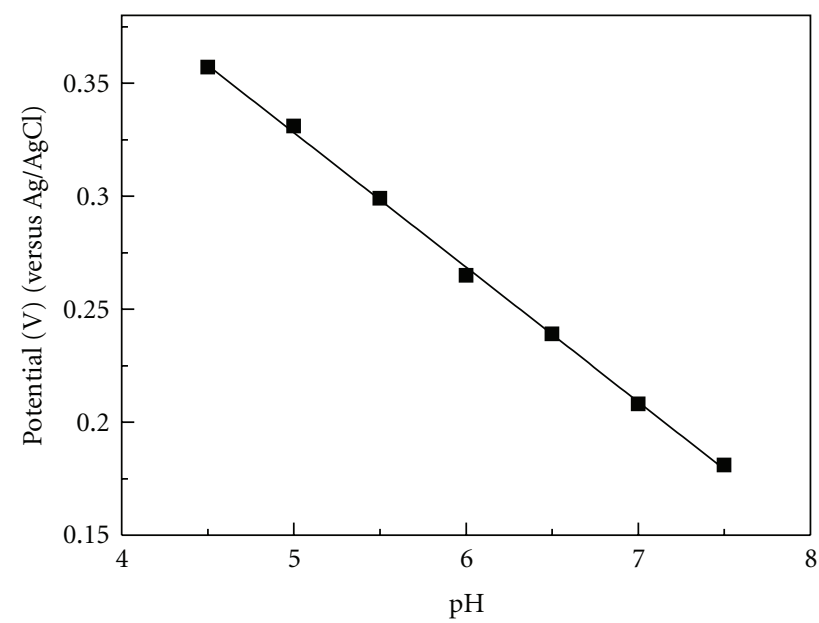

(b)

FIGURE 6: (a) Effect of pH value on the peak current of DA; (b) Effect of pH value on the anodic peak potential of DA.

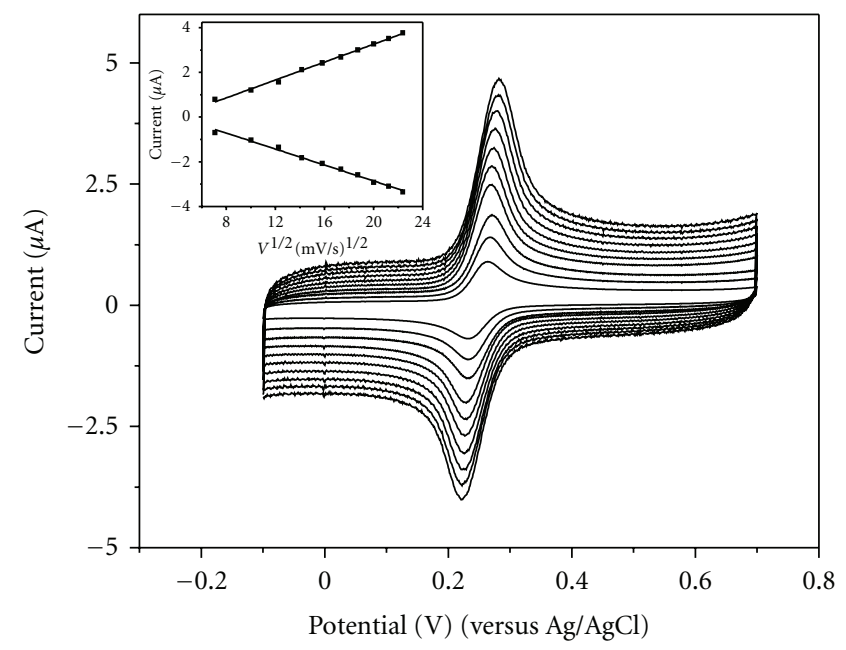

FIgure 7: Cyclic voltammograms for the oxidation of DA at the CNF-CPE in $0.1 \mathrm{M}$ PBS (pH 6.0). Scan rate: 50, 100, 150, 200, $250,300,350,400,450$, and $500 \mathrm{mV} \mathrm{s}^{-1}$. Inset plot shows the peak current versus square root of scan rate.

potential of DA oxidation exhibits more negative with the anodic and cathodic peak potential at $365 \mathrm{mV}$ and $308 \mathrm{mV}$ at the CNF-CPE. The peak-to-peak separation is $57 \mathrm{mV}$, which indicates that electron transfer is fast at the CNF$\mathrm{CPE}$. Furthermore, the redox current of $\mathrm{DA}$ at the $\mathrm{CNF}$ modified electrode is higher than that at the bare $\mathrm{CPE}$, which demonstrates that CNF modified electrode has a remarkable catalytic activity to the redox process of DA in contrast to the bare CPE. The superior electrocatalytic activity of the CNF-CPE is mainly ascribed to the higher proportion of oxygen-functional groups presented on the surface of CNF, and large effective electroactive surface area. In addition, the oxygen-rich groups on the surface of CNF made the modified electrode negatively charged, while DA $(\mathrm{pKa}=8.9)$ was positively charged in $0.1 \mathrm{M}$ PBS ( $\mathrm{pH} 4.5$ ). Therefore, high redox current at the CNF-CPE can be attributed to the adsorption of DA.

In order to further investigate the electrochemical behavior of DA at CNF-CPE, the effect of $\mathrm{pH}$ value on the determination of DA at the CNF-CPE was carefully investigated by cyclic voltammograms in a wide $\mathrm{pH}$ range ( $\mathrm{pH}$ 4.5-7.5). Figure 6(a) shows cyclic voltammograms of DA in $0.1 \mathrm{M}$ PBS with different $\mathrm{pH}$ value at the CNF-CPE. It can be observed that the peak current of DA increases with a higher $\mathrm{pH}$ value until it reaches 6.0 , and then it decreases with a higher $\mathrm{pH}$ value. In order to obtain high sensitivity, $\mathrm{pH} 6.0$ was selected as an optimum $\mathrm{pH}$ value for the determination of DA. Figure 6(b) illustrates the relationship between the anodic peak potential (Epa) of DA and the $\mathrm{pH}$ value of solution. It can be found that the anodic peak potential of DA shifts negatively as the increase of the $\mathrm{pH}$ value of solution and is linear with the $\mathrm{pH}$ value in the range from 4.5 to 7.5 . The corresponding linear equations is Epa $=-59.5 \mathrm{pH}+0.626$ with a slop of $59.5 \mathrm{mV} / \mathrm{pH}(r$ $=0.998$ ). It demonstrates that the redox of DA undergoes a two-electron and two-proton process, which is consistent with the previous reports [20].

Cyclic voltammograms was used to investigate the electrochemical behavior of DA with the different scan rate in the range from 50 to $500 \mathrm{mV} \mathrm{s}^{-1}$. Figure 7 shows that the peak current of DA at the CNF-CPE is proportional to the scan rate in the range from 50 to $500 \mathrm{mV} \mathrm{s}^{-1}$. It is found that the anodic and cathodic peak currents increase as the increase of the scan rate. The inset plot exhibits the corresponding plot of peak currents versus scan rate. The anodic and cathodic peak currents are linear with the square root of scan rate and the corresponding linear equations for anodic and cathodic peak currents are $i_{\mathrm{a}}=0.200 v^{1 / 2}-0.7396(r=0.995)$ and $i_{\mathrm{c}}=-0.1785 v^{1 / 2}+0.7119(r=0.992)$, and indicates that the electrochemical oxidation of DA at the CNF-CPE is a diffusion-controlled process [7]. 


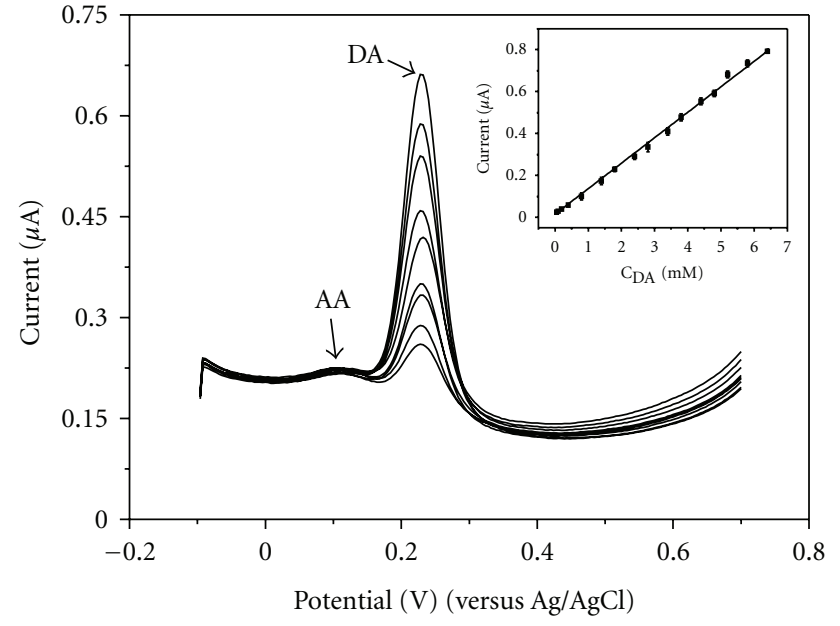

FIGURE 8: Differential pulse voltammograms at the CNF-CPE for AA $(5 \mu \mathrm{M})$ in the presence of DA with different concentrations: (a) 0.4 , (b) 0.6, (c) 0.8, (d) 1.0, (e) 1.4, (f) 1.8, (g) 2.0, (h) 2.4, and (i) $2.8 \mu \mathrm{M}$. DPV measurements were performed from -0.1 to $0.7 \mathrm{~V}$ with the pulse amplitude of $50 \mathrm{mV}$ and the pulse width of $50 \mathrm{~ms}$. Inset plot shows the dependence of the response currents of the CNF-CPE electrode on the concentration of DA in $0.1 \mathrm{M}$ PBS $(\mathrm{pH}$ $6.0)$.

3.3. Determination of Dopamine. Differential pulse voltammetry (DPV) was used for the detection of DA in the presence of AA. Figure 8 shows the DPV of DA with various concentrations in the presence of $5 \mu \mathrm{M}$ AA at the CNF-CPE. It can be obtained that the anodic peak potential of DA and $\mathrm{AA}$ at $228 \mathrm{mV}$ and $120 \mathrm{mV}$, and the peak-to-peak separation is about $110 \mathrm{mV}$. The oxidation current of DA shows a linear relationship with the DA concentration from $0.05 \mu \mathrm{M}$ to $6.4 \mu \mathrm{M}$. Moreover, the peak current of AA remains nearly unchanged with the increase of DA concentration, which demonstrates that the response of DA is not interfered in the presence of $5 \mu \mathrm{M}$ AA. The inset plot in Figure 8 shows the corresponding results of the DPV curves of DA with different concentrations at the CNF-CPE. The linear regression equation for the response of DA can be expressed as Ip $(n A)=121.5 \mathrm{c}(\mu \mathrm{M})+15.2$ with a correlation coefficient of 0.998 . The detection limit is $0.05 \mu \mathrm{M}$ at signal-to-noise ratio (SNR) of 3 , and the linear range is 0.05 to $6.4 \mu \mathrm{M}$. The detection limit obtained in this work is lower than that at the cetylpyridinium bromide (CPB) modified SWCNTs [21] and thionine-nafion modified multiwalled carbon nanotube [22]. Comparing the linear range of dopamine obtained at the CNF-CPE with the previous reports $[21,22]$, the linear range at the CNF-CPE is not very wide, for the adsorption of DA at the CNF-CPE would affect the detection of dopamine.

The reproducibility and stability of the electrode were investigated. The reproducibility for $0.1 \mu \mathrm{M}$ DA at the CNFCPE was recorded with the RSD of $5.5 \%(n=3)$. The DPV response of $4.8 \mu \mathrm{M}$ DA at the CNF-CPE remained $96 \%$ after seven days. All the results above indicate that the CNF-CPE exhibits a good reproducibility and stability.
TABle 1: Determination of DA in dopamine hydrochloride injection.

\begin{tabular}{lccc}
\hline DA specified $(\mu \mathrm{M})$ & Added $(\mu \mathrm{M})$ & Found $(\mu \mathrm{M})$ & Recovery $(\%)$ \\
\hline 2.1 & 0 & 1.8 & - \\
2.1 & 1 & 3.3 & 106.4 \\
2.1 & 2 & 4.2 & 102.4 \\
2.1 & 3 & 4.6 & 92 \\
\hline
\end{tabular}

3.4. Determination of DA in Dopamine Hydrochloride Injection. The method for analysis of DA was used in pharmaceutical product to verify the reliability. This CNF-CPE was applied to determine DA in dopamine hydrochloride injection ( $10 \mathrm{mg} \mathrm{mL}^{-1}$ per injection). First, the sample was diluted 10 times with double distilled water, and then appropriate amounts of the diluted sample were transferred into the electrochemical cell for the determination using DPV. The analytical results are summarized in Table 1. It can be observed that the recovery ranges from $92 \%$ to $106.4 \%$, which is acceptable for practical analysis.

\section{Conclusions}

A new method was employed to pretreat the CNF, which was timesaving and effective. The resulting CNF showed good hydrophilic, high electrochemical activity, and large effective electroactive surface area, owing to the presence of the oxygen-rich groups. The electrochemical redox behavior of DA was improved obviously at the CNF-CPE. Furthermore, AA with high concentration did not alter the response of CNF-CPE toward the oxidation of DA. For the determination of DA, CNF-CPE showed good characteristics, high sensitivity and selectivity.

\section{Acknowledgments}

The authors are grateful for the financial support from the National Natural (no. 20875085) and Chinese Academy of Sciences (no. KJCX2-YW-H11).

\section{References}

[1] L. Wu, X. Zhang, and H. Ju, "Detection of NADH and ethanol based on catalytic activity of soluble carbon nanofiber with low overpotential," Analytical Chemistry, vol. 79, no. 2, pp. 453-458, 2007.

[2] S. Deng, G. Jian, J. Lei, Z. Hu, and H. Ju, "A glucose biosensor based on direct electrochemistry of glucose oxidase immobilized on nitrogen-doped carbon nanotubes," Biosensors and Bioelectronics, vol. 25, no. 2, pp. 373-377, 2009.

[3] C. Xu, J. Chen, Y. Cui et al., "Influence of the surface treatment on the deposition of platinum nanoparticles on the carbon nanotubes," Advanced Engineering Materials, vol. 8, no. 1-2, pp. 73-77, 2006.

[4] H. R. Zare, N. Rajabzadeh, N. Nasirizadeh, and M. Mazloum Ardakani, "Voltammetric studies of an oracet blue modified glassy carbon electrode and its application for the simultaneous determination of dopamine, ascorbic acid and uric acid," 
Journal of Electroanalytical Chemistry, vol. 589, no. 1, pp. 60 69, 2006.

[5] Y. Xiao, C. Guo, C. M. Li et al., "Highly sensitive and selective method to detect dopamine in the presence of ascorbic acid by a new polymeric composite film," Analytical Biochemistry, vol. 371, no. 2, pp. 229-237, 2007.

[6] H. Zhu, W. Wu, H. Zhang, L. Fan, and S. Yang, "Highly selective and sensitive detection of dopamine in the presence of excessive ascorbic acid using electrodes modified with $\mathrm{c}_{60}$ functionalized multiwalled carbon nanotube films," Electroanalysis, vol. 21, no. 24, pp. 2660-2666, 2009.

[7] C. Deng, J. Chen, M. Wang, C. Xiao, Z. Nie, and S. Yao, "A novel and simple strategy for selective and sensitive determination of dopamine based on the boron-doped carbon nanotubes modified electrode," Biosensors and Bioelectronics, vol. 24, no. 7, pp. 2091-2094, 2009.

[8] A. Ciszewski and G. Milczarek, "Polyeugenol-modified platinum electrode for selective detection of dopamine in the presence of ascorbic acid," Analytical Chemistry, vol. 71, no. 5, pp. 1055-1061, 1999.

[9] J. Kang, L. Zhuo, X. Lu, and X. Wang, "Electrochemical behavior of dopamine at a quercetin-SAM-modified gold electrode and analytical application," Journal of Solid State Electrochemistry, vol. 9, no. 2, pp. 114-120, 2005.

[10] P. R. Roy, T. Okajima, and T. Ohsaka, "Simultaneous electroanalysis of dopamine and ascorbic acid using poly (N,N-dimethylaniline)-modified electrodes," Bioelectrochemistry, vol. 59, no. 1-2, pp. 11-19, 2003.

[11] J.-M. Zen and P.-J. Chen, "A selective voltammetric method for uric acid and dopamine detection using clay-modified electrodes," Analytical Chemistry, vol. 69, no. 24, pp. 50875093, 1997.

[12] A. Doménech, H. García, M. T. Doménech-Carbó, and M. S. Galletero, "2,4,6-Triphenylpyrylium ion encapsulated into zeolite $\mathrm{Y}$ as a selective electrode for the electrochemical determination of dopamine in the presence of ascorbic acid," Analytical Chemistry, vol. 74, no. 3, pp. 562-569, 2002.

[13] J. Huang, D. Wang, H. Hou, and T. You, "Electrospun palladium nanoparticle-loaded carbon nanofibers and their electrocatalytic activities towards hydrogen peroxide and NADH," Advanced Functional Materials, vol. 18, no. 3, pp. 441-448, 2008.

[14] D. T. Fagan, I. F. Hu, and T. Kuwana, "Vacuum heat treatment for activation of glassy carbon electrodes," Analytical Chemistry, vol. 57, no. 14, pp. 2759-2763, 1985.

[15] P. Chen and R. L. McCreery, "Control of electron transfer kinetics at glassy carbon electrodes by specific surface modification," Analytical Chemistry, vol. 68, no. 22, pp. 3958-3965, 1996.

[16] A. J. Plomp, D. S. Su, K. P. D. Jong, and J. H. Bitter, "On the nature of oxygen-containing surface groups on carbon nanofibers and their role for platinum depositionsan XPS and titration study," Journal of Physical Chemistry C, vol. 113, no. 22, pp. 9865-9869, 2009.

[17] H. Orikasa, N. Inokuma, S. Okubo, O. Kitakami, and T. Kyotani, "Template synthesis of water-dispersible carbon nano "test tubes" without any post-treatment," Chemistry of Materials, vol. 18, no. 4, pp. 1036-1040, 2006.

[18] C. Moreno-Castilla, M. V. López-Ramón, and F. CarrascoMarín, "Changes in surface chemistry of activated carbons by wet oxidation," Carbon, vol. 38, no. 14, pp. 1995-2001, 2000.

[19] S. Hou, N. Zheng, H. Feng, X. Li, and Z. Yuan, "Determination of dopamine in the presence of ascorbic acid using poly (3,5-dihydroxy benzoic acid) film modified electrode," Analytical Biochemistry, vol. 381, no. 2, pp. 179-184, 2008.

[20] S. Jiao, M. Li, C. Wang, D. Chen, and B. Fang, "Fabrication of Fc-SWNTs modified glassy carbon electrode for selective and sensitive determination of dopamine in the presence of AA and UA," Electrochimica Acta, vol. 52, no. 19, pp. 59395944, 2007.

[21] Y. Zhang, Y. Pan, S. Su, L. Zhang, S. Li, and M. Shao, "A novel functionalized single-wall carbon nanotube modified electrode and its application in determination of dopamine and uric acid in the presence of high concentrations of ascorbic acid," Electroanalysis, vol. 19, no. 16, pp. 1695-1701, 2007.

[22] S. Shahrokhian and H. R. Zare-Mehrjardi, "Application of thionine-nafion supported on multi-walled carbon nanotube for preparation of a modified electrode in simultaneous voltammetric detection of dopamine and ascorbic acid," Electrochimica Acta, vol. 52, no. 22, pp. 6310-6317, 2007. 

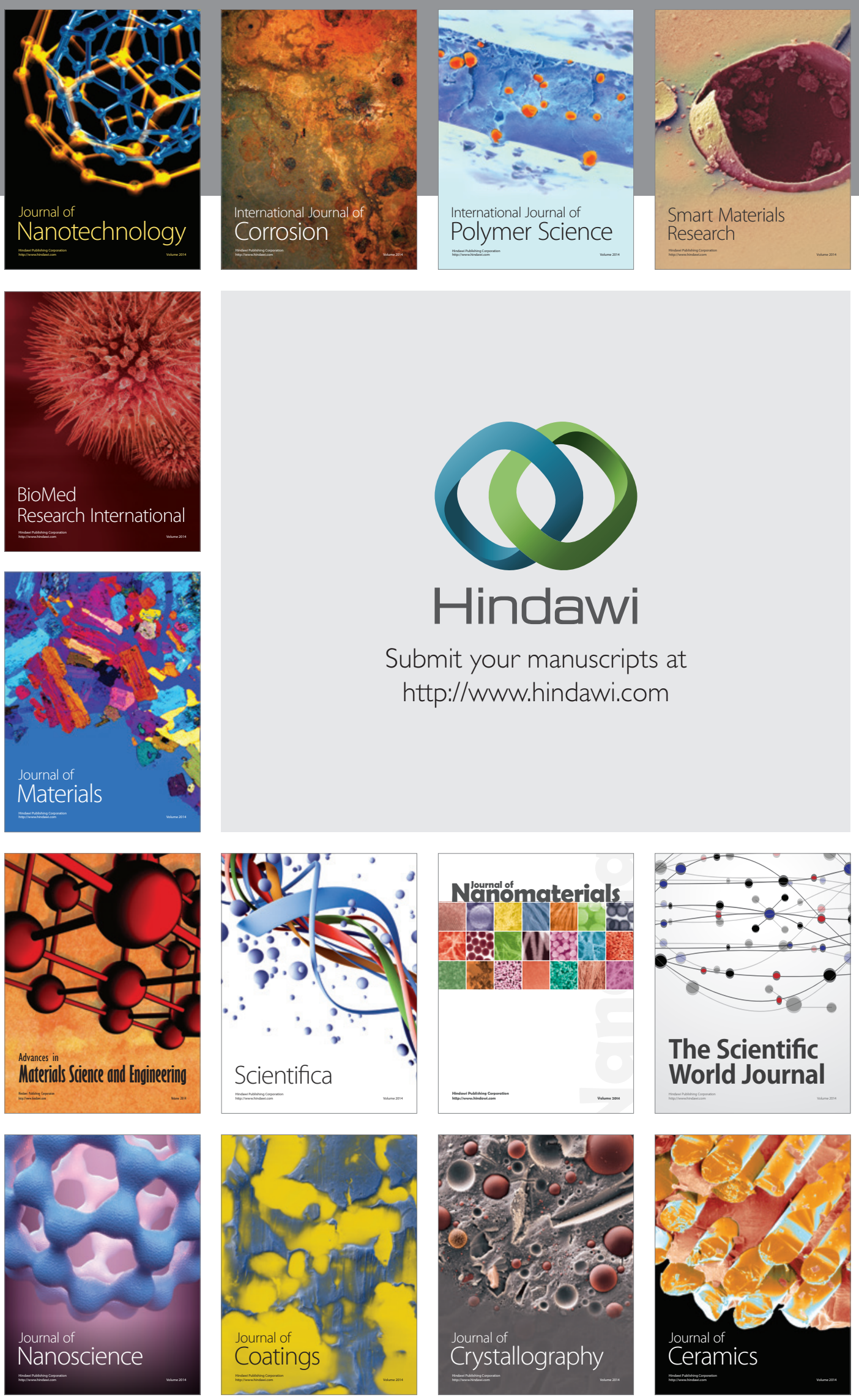

The Scientific World Journal

Submit your manuscripts at

http://www.hindawi.com

\section{World Journal}

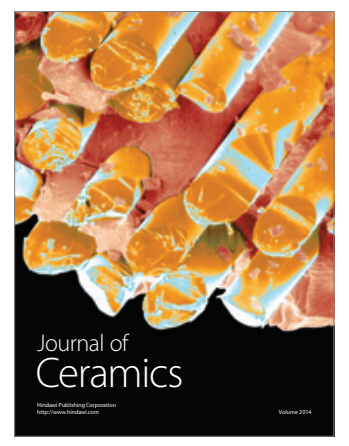

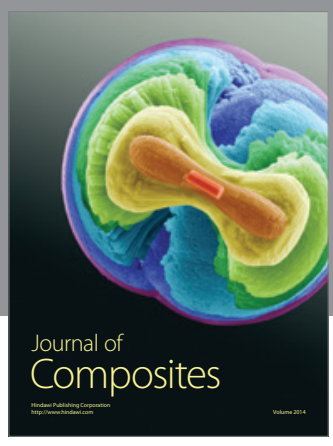
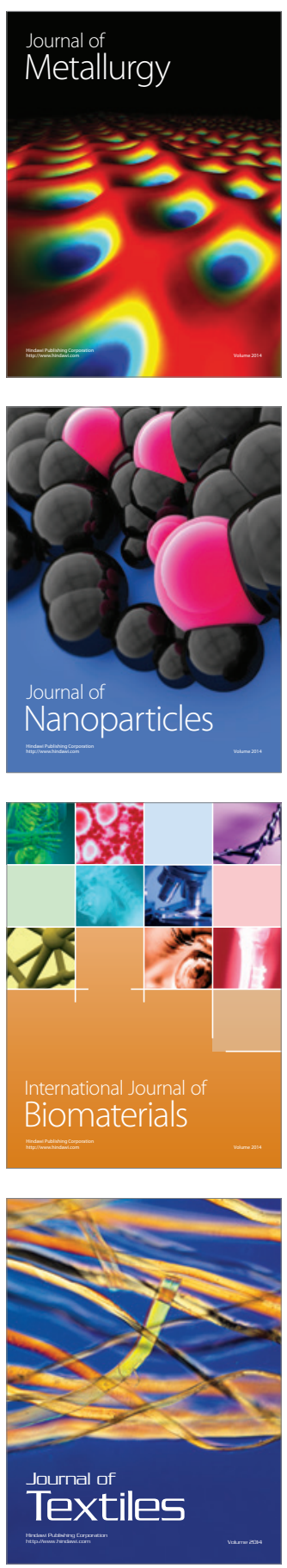